\title{
The User Experience in Zen and the Art of Motorcycle Maintenance
}

DOI:

$10.1145 / 2851581.2892566$

\section{Document Version}

Accepted author manuscript

Link to publication record in Manchester Research Explorer

\section{Citation for published version (APA):}

Harper, S. (2016). The User Experience in Zen and the Art of Motorcycle Maintenance. In CHI EA '16 Proceedings of the Proceedings of the 2016 CHI Conference Extended Abstracts on Human Factors in Computing Systems (pp. 317-327). Association for Computing Machinery. https://doi.org/10.1145/2851581.2892566

\section{Published in:}

CHI EA '16 Proceedings of the Proceedings of the 2016 CHI Conference Extended Abstracts on Human Factors in Computing Systems

\section{Citing this paper}

Please note that where the full-text provided on Manchester Research Explorer is the Author Accepted Manuscript or Proof version this may differ from the final Published version. If citing, it is advised that you check and use the publisher's definitive version.

\section{General rights}

Copyright and moral rights for the publications made accessible in the Research Explorer are retained by the authors and/or other copyright owners and it is a condition of accessing publications that users recognise and abide by the legal requirements associated with these rights.

\section{Takedown policy}

If you believe that this document breaches copyright please refer to the University of Manchester's Takedown Procedures [http://man.ac.uk/04Y6Bo] or contact uml.scholarlycommunications@manchester.ac.uk providing relevant details, so we can investigate your claim.

\section{OPEN ACCESS}




\section{The User Experience in Zen and the Art of Motorcycle Maintenance}

Simon Harper

University of Manchester

Manchester, M13 9PL, UK

simon.harper@manchester.ac.uk
Permission to make digital or hard copies of all or part of this work for personal or classroom use is granted without fee provided that copies are not made or distributed for profit or commercial advantage and that copies bear this notice and the full citation on the first page. Copyrights for components of this work owned by others than the author(s) must be honored. Abstracting with credit is permitted. To copy otherwise, or republish, to post on servers or to redistribute to lists, requires prior specific

permission and/or a fee. Request permissions from Permissions@acm.org. CHI'16 Extended Abstracts, May 7-12, 2016, San Jose, CA, USA. Copyright is held by the owner/author(s). Publication rights licensed to ACM. (-) 2016 ACM 978-1-4503-4082-3/16/05 ...\$15.00. http://dx.doi.org/10.1145/2851581.2892566

\begin{abstract}
How do we teach $\mathrm{UX} / \mathrm{HCl}$ concepts to an audience who have not encountered the domain before? We thought the learning process may be best supported by using material which might be more compelling. Zen and the Art of Motorcycle Maintenance (ZAMM) is a classic and accessible work of American literature, often taught at college or as part of University degrees. Published in 1974 ZAMM is a first person account of a 17-day motorcycle journey from Minnesota to Northern California by the author and his son. Surprisingly, we encouraged reading ZAMM as a method of learning the over arching issues in $\mathrm{HCl}$ and $\mathrm{UX}$. Even more surprisingly, students reported benefits in the comprehension of $\mathrm{HCl} / \mathrm{UX}$ topics from reading it.
\end{abstract}

\section{Author Keywords}

Teaching; Learning; Pedagogy; HCl; User Experience; UX; Zen and the Art of Motorcycle Maintenance; ZAMM; Robert M. Pirsig

\section{General Terms}

Human Factors; Documentation; Design

\section{ACM Classification Keywords}

H.5.1 [Information interfaces and presentation (e.g., $\mathrm{HCl}$ )]: Multimedia Information Systems.; H.5.2 [Information interfaces and presentation (e.g., $\mathrm{HCl}$ )]: User Interfaces. 


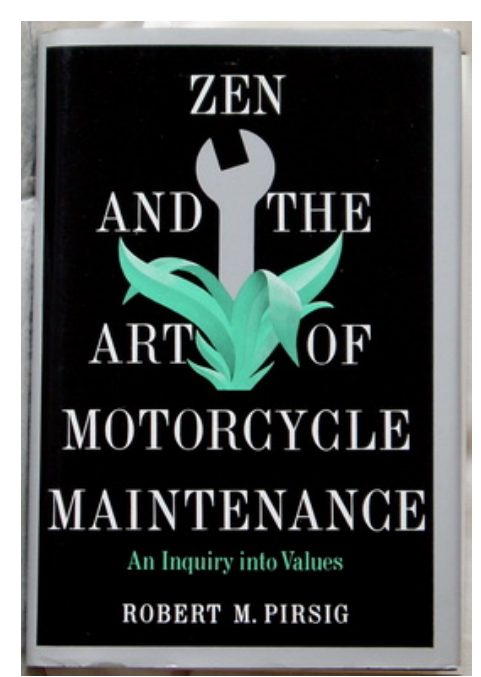

Photograph of ZAMM Cover. Credit: Unattributed, 2011.

Rights: Wikimedia, 2011. Qualifies as fair use under United
States law Section 107 of the Copyright Act

\section{Introduction}

Zen and the Art of Motorcycle Maintenance (ZAMM) [10] - published in 1974 by Robert M. Pirsig ${ }^{1}$ - may seem like a strange text to use for a Computer Science based UX text; but it isn't. In reality ZAMM is not really about Zen or indeed motorcycle maintenance, it's about science, quality, and rhetoric. Pirsig examines the modern pursuit of 'Pure Truths', claiming it derives from the work of early Greek philosophers who were establishing the concept of truth in opposition to the force of 'The Good'. He argues that although rational thought may find a truth it may never be fully and universally applicable to each and every individual's experience. Therefore, what is needed is an approach to viewing life that is more varied and inclusive and has a wider range of application. We noticed conceptual similarities with the classical quantitative Human Computer Interaction $(\mathrm{HCl})$ and 'the new' User Experience (UX). In this case, we thought the learning process may be best supported by 'piggy-backing' this new domain on a user's preexisting knowledge and by using material which might be more easily 'digested' or is more compelling.

Here we explain why the concepts contained within it are a useful pre-cursor to learning $\mathrm{UX} / \mathrm{HCl}$, how theses relate to the understanding and practice of UX within a professional setting, and how different texts might be used to enhance comprehension in other domains.

\section{The Collision of Two Opposing Ideologies}

In the past we characterised practical $\mathrm{HCl}$ in terms of usability and interaction engineering (in some cases accessibility was included but mainly as an afterthought). In this case, we decided if an interface was 'usable' and the interaction design was 'good', based on tangible, measurable

\footnotetext{
stated.
}

metrics such as task completion time. These kinds of metrics enabled us to understand the interactive experience in terms of time, theorising that the least time spent using the interface, the better. This may have been, in some ways correct, as most computers were used in work situations.

As time passed our concept of the computer and the interface evolved such that computers were no more tied to the desktop but could be mobile or ubiquitous. And the interface was not solely confined to software but may also include aspects of hardware, moving computers from the workplace and into the consumer product domain. Our ways of measuring and valuing the goodness of these interfaces however remained the same, task completion time, errors and error rates, correction times, Fitts Law pointing predictions, etc. Indeed this was the scientific or classical view of technology. At this point intangibles were seen as being soft science, unmeasurable and too open to incorrect interpretation. Other aspects, which might also affect how interfaces were experienced, but which could not be directly measured, and which relied more on subjective views of the user was seen as being, at best inconsequential, and at worst just plain old bad-science.

This clash of ideologies runs large through the whole of Zen and the Art of Motorcycle Maintenance, its main theme being how to unify both the scientific and the romantic; the classic and the aesthetic; the tangible and the intangible; the measurable and the experiential. ZAMM tries to rhetorically unite these two opposing ideologies via a quality framework, indeed this rhetorical attempt eventually sends the author insane; happily this is not the case with practical $\mathrm{HCl}$.

$\mathrm{UX}$ is our attempt to unite classic $\mathrm{HCl}$ with modern ideas of experience and perception in which accessibility, usability, and interaction engineering (tangible, scientific, measur- 
able) are combined with aesthetic, emotional, fun, affective, collaborative, and gameplay (intangible, humane, difficult to measure).

By understanding the clash of worlds as discussed at length in ZAMM we can also understand the more successful combination of these two - seemingly opposing - ideologies into a unified and cohesive whole as practically applied in UX. By understanding the nuances as discussed in ZAMM, we can better understand what issue we will need to overcome in future UX design, build, and evaluation and also begin to value - and better understand - the subjective qualitative views of the interactive experiences of our users.

\section{Perception of the User Experience}

One of the other major themes of ZAMM is that of perception $^{2}$, and the differences which lie between people and their experience of the world. At its most trivial this can be seen in the realisation that all $\mathrm{Chris}^{3}$ has been able to see for hundreds of miles is the back of his father - until he stands up - and that this is in someway responsible for Chris' boredom and behaviour. However, more deeply the perception of reality for the different protagonists and how that reality is experienced is discussed in detail. This runs from how Chris experiences driving a car when his father is unable to function properly, through to the imposition of normality expected of the author by the society in which he lives, and culminating in the annihilation of his personality 4 . Through to the perception of the authors friends in Boze-

2Both perception meaning 'looking around' [8] as well as in a more complex form as a cognitive psychologist would understand it.

${ }^{3}$ Chris is Pirsig's son, and spends his time on the motorcycle sat behind his Father.

${ }^{4}$ after electroconvulsive therapy. man $^{5}$ who do not understand that the person they knew does not now exist.

These complicated experiences and perceptions of experience should be taken as warnings to anyone working in user experience. Our perceptions are complicated and incredibly difficult to categorise. What may seem to be obvious to one person, may be obscure to another. User experience, as opposed to classical $\mathrm{HCl}$, takes these different subjective perceptions into account in its desire to create practical pleasing experiences for each user.

Perception is something not normally measured or quantified in classic $\mathrm{HCl}$ and so only in the modern additions of emotion, fun and dynamic interaction can these intangibles be acknowledged. Further, in his interview with 'The Guardian' Newspaper Pirsig highlights these perceptual differences:

'I ask what Chris thought of the book, and Pirsig's face strains a little. "He didn't like it. He said, -Dad, I had a good time on that trip. It was all false.- It threw him terribly".. [1]

ZAMM shows us that experience can be massively divergent, and that outliers are as important as the general cases (if not more so). By intertwining stories of two different personalities in the same person, and understanding the perceptions - explicitly discussing these perceptions of experience from different protagonists, ZAMM becomes a valuable teaching tool for UX. It could be though of as one large 'Agile Scenario'.

${ }^{5}$ Bozeman is a city in Gallatin County, which hosts the Montana State University, at which Pirsig taught creative writing 


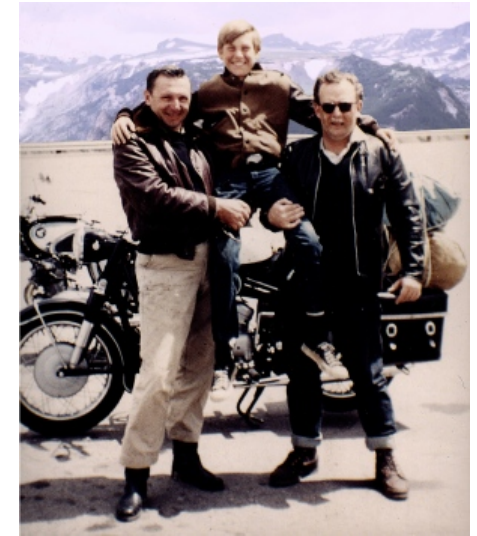

Robert Pirsig (left) found the inspiration for his book, Zen and the Art of Motorcycle Maintenance, during a road trip he took through Minnesota in 1968 with his son Chris (centre) and philosophy buddy John Sutherland. Credit: Robert Pirsig, 1968 Rights: CBC, 2014 [11]. Qualifies as fair use under United
States law Section 107 of the Copyright Act.
The Discussion and Framing of Science in the User Experience In its comparison of subjective and objective paradigms the classical and the romantic-ZAMM does an excellent job of conveying the nature of the scientific method and the work that stems from it. Indeed, in its discussion of empiricism, ZAMM also discusses objectivity and the belie systems that arise around both objectivity and subjectivity.

The discussion of science and its limitations are also pursued. In this case, we can see that most of Pirsig's students share a common understanding of quality, in that they can tell quality when they see it, but quality is difficult to measure in any empirical or objective way; or describe with any degree of clarity. It seems in some ways an emergent property, or an umbrella term under which other more easily measured objective indicators can play a part. However, the richness of the description of quality is difficult to place only in such objective terms. So we can see that science cannot be the only measure of user experience, because science is mostly about generalisation, and because we do not have a full model of the universe; we therefore do not know all the variables which may arise to influence the user experience of a single individual. By nature we must conclude, in some regard, that objective, empirical science cannot give us all the answers at this time (until our model is complete), only the answer to testable questions.

This discussion of science is directly related to our discussions of the application of user experience, how we understand modern user experience, and how older styles of human computer interaction serve as an excellent base, but cannot provide the richness which is associated with the intangible, and often unquantifiable subjective, and emotional aspects which we would expect any user experience to comprise of.
We must, however, be cautious. By suggesting that subjective measures may not be testable means that we may be able to convince ourselves and others that a system is acceptable, and even assists or aids the user experience. While in reality there is no evidence, be it theoretical or experimental, which supports this argument. It may be that we are using rhetoric and argumentation to support subjective measures as a way of sidestepping the scientific process which may very well disprove our hypotheses as opposed to support it.

The Conceptualisation of Theoretical and Empirical User Experience

Notice, in the last section we discussed one fundamental of science, the fact that we can disprove or support a hypothesis, in empirical work we cannot prove one. We cannot prove a hypothesis because in the real world we are not able to test every single condition that may be applied to the hypothesis. In this case, we can only say that our hypothesis is strong because we have tried to destroy it and have failed. But now notice that in ZAMM this is not the case.

Pirsig, is trained in rhetoric, in theoretical not empirical work, and so his conception of science is different to ours. In theoretical science (the science Pirsig is familiar with) it is quite possible to prove or disprove the hypothesis. This is because the model of the world is known in full, all tests can be applied, all answers can be evaluated. This is especially the case with regard to mathematics or theoretical physics whereby the mathematical principles are the way the world is modelled, and this theoretical world works on known principles. However this is not the case in user experience, and it is not the case in empirical science whereby we are observing phenomena in the real world and testing our theories using experiments; which may be tightly controlled, but are often as naturalistic as possible. In this case, it is not 
possible to prove a hypothesis, because our model of the world is not complete, because we do not know the extent of the world, or all possible variables, in complex combination, which are able to affect the outcome.

In real-world empirical work we only need one negative result to disprove our hypothesis, but we need to have tested all possibilities to prove our hypothesis correct; we just don't know when everything has been tested.

Rhetoric, Argumentation, and the User Experience So, how can we satisfy ourselves that subjective, or intangible factors are taken into account in the design process and afterwards. ZAMM provides us with an answer in the form of rhetoric and argumentation. While we may not be able to measure the subjective outcomes or directly generalise them we are able to rationalise these aspects with logical argumentation. And rhetoric - the art of using language effectively so as to persuade or influence others can obviously play a key role in this. However, you will notice that the problem with rhetoric is that while you may be able to persuade or influence others, especially with the aid of logical argumentation, your results and premise may still be incorrect. Indeed, these failures are also discussed within ZAMM whereby the author discusses rhetorical debates within his University of Chicago Ph.D. program, but which seem to have little concrete outcome even though the rhetoric is built upon seemingly solid logical and rhetorical foundation. Pirsig, at first fails to 'win' his rhetorical encounter with his supervisor - but then successfully argues the same point and does 'win'. Notice that the point is the same, win or loose. If you haven't thought of or don't predict the [counter]arguments that will be made, and have your own convincing counter arguments you'll loose. You may be right, but if you are, your arguments and counter argu- ments should be complete, that's the point of rhetoric and rhetorical debate.

Remember though, that with the user experience it is not our job to win an argument just for the sake of argumentation or rhetoric itself. We are not there to prove our eloquence, but we are there to support our inductive and deductive reasoning, and our own expertise (Pirsig calls this 'feel' when he refers to it in the context of mechanical repair) when it comes to understanding the user experience within the subjective or intangible.

Further, Pirsig elucidates 'feel' by telling us that:

'The difference between a good mechanic and a bad one, like the difference between a good mathematician and a bad one, is precisely this ability to select the good facts from the bad ones on the basis of quality. He has to care! This is an ability about which formal traditional scientific method has nothing to say.

Values, and the Intangible Nature of the User Experience ZAMM's subtitle is 'An Inquiry into Values' and it is useful to remember this in the context of understanding the user experience. In reality, many of the intangibilities which arise in UX work stem from these often hidden values. Values which are expressed throughout the book, from when Pirsig describes his experiences with motorcycle mechanics who may be competent but do not seem to place a value on their work or their ability to fix, in this case, tappets, to John Sutherland's ${ }^{6}$ view of 'shims'.

${ }^{6}$ John Claire Sutherland, artist and musician, is a friend of Pirsig's from Minneapolis. With his wife, Sylvia, John accompanies Pirsig and Chris to Bozeman, Montana. 


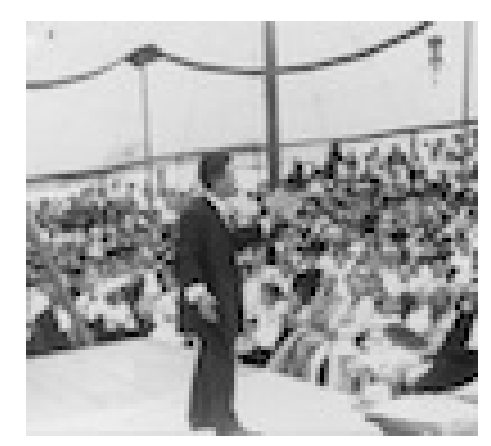

Gov. LaFollette of Wisconsin addressing a Chautauqua assembly, Decatur, III. c. 1905. Credit: C.L. Wasson, 1905

Rights: Wikimedia, 2006. This media file is in the public domain
in the United States.
More interestingly however, Pirsig discusses the values which are related to the world-views of the people he is with; the Sutherland's. Indeed he uses the Sutherland's to play the counterpart to his mechanical, logical, functional view; the Sutherland's being romantic, aesthetic, and emotional. Again, denoted by the discussion surrounding John's view of the 'shim' created from a can as opposed to that created for the specific purpose and so therefore more aesthetically appealing.

The point here that Pirsig is trying to make is that people bring their own values based on previous experience and their emotional state of equilibrium to any experience.

These aspects are intangible and can be difficult to spot especially with regard to understanding the user experience. However, we can also use these values and world-views (if we have some idea of them) to positively influence users emotional response to an interface or interaction. Remember, others have discussed that the expectation or perception of an experience, be it good or bad, will influence to a large degree the perception of that actual experience once enacted.

The ZAMM Narrative Enhances the User Experience Finally, let us consider ZAMM in more broader terms. We would imagine that if you have read the book you would have immediately seen the principles and concepts that have been discussed here [2]. It is often very difficult to make textbooks as engaging as a good story, especially when its overarching ideas and viewpoints you're trying to convey.

Placing these ideas into a more digestible form (such as the use of ZAMM, or Pirsig's use of Chautauquas ${ }^{7}$ ) is like

${ }^{7}$ An adult education movement in the United States, highly popular in the late nineteenth and early twentieth centuries. slipping broccoli into a big Mac, or a vitamin supplement into Coco-hoops. We already know that stories and narrative are a key aspect of usability or 'efficient experience' because they enhanced learnability. This said, key aspects may be lost in the general narrative if they're not signposted or pointed out.

\section{Pedagogy}

There are many reading lists available espousing the books a UX education should include. Indeed, our own course notes suggest many of the most central and relevant academic texts. Further, there are also many reading lists for those UX practitioners self-educating online [3]. And ${ }^{8}$ those that describe off-domain texts which may have some relevance to $\mathrm{UX} / \mathrm{HCl}$ but are sourced from other disciplines [9, 4]. However, these are all presented in the style of the instructional 'textbook', 'technical manual', or non-fiction monograph. Choosing popular narrative works to convey complex technical messages is neither common not obvious. It seems to us that we have an inbuilt affinity for storytelling and narrative. Visual art, music, theatre, and film most commonly convey a narrative message, a story which has resonance to the recipient. Why then might this not be the case with science? Indeed, we would suggest that more of our textbooks should aim to introduce concepts with illustrative stories which our audience can relate to. In the absence of such texts we, as academics, must make the links ourselves by pairing stories with technical explanation and elucidation.

\section{What About the Students?}

The unit on which ZAMM was optional reading has run as part of a final year CS programme in the UK system for students with no prior exposure to either $\mathrm{HCl}$ or UX. The unit is live, and has run for five years with around 100

\footnotetext{
${ }^{8}$ We have found just one list, and one philosophical underpinning.
} 
students per year taking it as an option. Of these around $30 \%$ read ZAMM with no credit, and of these $80 \%$ anecdotally self-reported an increased comprehension of the $\mathrm{HCl}$ and $\mathrm{UX}$ concepts highlighted in ZAMM while feeling no such improvement in those concepts of the unit not covered in ZAMM, even when those concepts where repeated/recovered multiple times. As expected those students not reading ZAMM felt no increased comprehension of any topic.

As you can see, this isn't 'science' - certainly it does not follow the scientific method - the work only relates to anecdotal reports of the usefulness of a piece of teaching material to us, and so represents hearsay. The reading was optional, it was not examined directly (as examination scripts are anonymised at this University to remove possible marking bias), students reported reading ZAMM and anecdotally discussed ZAMM in the videoed lectures (and more completely off-camera which removed identity issues). Further, ethical approval was not possible as it was considered that this may influence the teaching and learning process or hinder it. So in short, you may not believe there is an easy link between ZAMM and UX, or that using more compelling and easily digestible material moved across domains is useful, further you'd be right to point out that this was not a scientific study. Ultimately, there is no clear empirical result (that student understanding improved) we can point to, and so we cannot show an analysis of this data. We are not able to discuss if the effects were marginal, if they were highly variable between students, or explain outliers.

We can however elucidate on the context of the students' experience with the book. Students where informed that ZAMM should be read but that it was optional and not examinable. But that reading it would help them to understand the concepts presented on the UX course. Every week the students where reminded, as we encouraged those that had started to read ZAMM to reflect on their experiences. What did they think the book brought as a learning experience? How did it effected their outlook on UX and the $\mathrm{HCl}$ ? Did they think it helped them understand UX? Would they continue reading it?

We know, we know. Like we say this is not empirical, but anecdotal hearsay which we think many academics may benefit from. In the end, do not take our word for it, just try it with your own students to see if you get the same positive responses we get. What is there to loose?

\section{Notes on How to Apply}

How then might this kind of pedagogic technique be applied more widely? Just as very good paper has a narrative at its heart, so does every unit/course. The first thing to do is decide on the story (the narrative), identify the concepts and principles you wish to convey, along with the counterpoints and issues that are contained within the domain.

The specifics of the course are not amenable to this technique, rather the conceptual framework and overarching narrative introduce students to the topic. Once you have these you are able to use them in the same way you might use a systematic literature review [5], but using the terms identified, coupled with a Google Book Search, Goodreads Search, or the like. It may also be that you already have a book in mind, or one comes to mind once you have identified the high level components of your course. Once you have selected your target texts then you need to read them to identify if they really will work for you, and you should also use online reviews, or discussions, to assess how compelling the books are, especially to your target audience. 


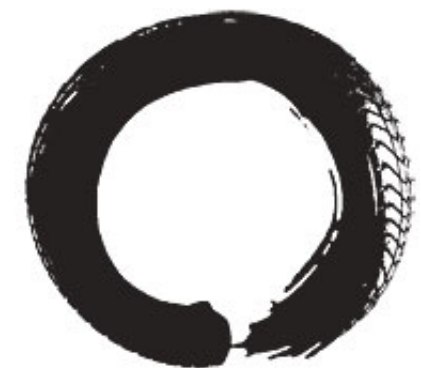

Credit: Oliver Munday, 2008. Rights: Reproduced with express permission of the artis.
You may also wish to assess if your students will have been exposed to the book in a different course beforehand. Indeed, you may wish to choose from reading lists of courses already taken in earlier years or from National Curricula.

\section{Conclusions and Future Work}

In reality, neither the selection of ZAMM, or this way of thinking about how to teach UX, came from some great overarching vision, but rather by mistake, or at least if not mistake, by happy accident. We started to develop the course around Effie Law's excellent CHI 2009 survey of UX [6] synthesised with a number of other research papers and books. These formed a unit which starts off at broad domain landscapes and concepts then drills down to present illustrative examples. We only stumbled across the similarities between the two after re-reading ZAMM on vacation. Then when discussing the concepts in ZAMM informally with students we realised that it helped them understand those related concepts in our UX course. In this case, how a course would fare which teaches very low level technical specifics as opposed to higher level concepts and the domain landscape is currently difficult to assess.

So is it just something about ZAMM that lends itself to this kind of 'companion learning' ('companion narrative'? 'supporting text'?). We don't think so, even though both the authors experiences and the cultural context of the work are significant. The experiences of ZAMM occurred after the Second World War in a period of societal change. The events of ZAMM are a culmination and memoir of 15 years through the 1950s and 60s. The trip occurring around 1968 and the book being written over 4 years, finally being published in $1974^{\circ}$. These years were seminal in American

${ }^{9}$ ZAMM was originally 800,000 words, was rejected by 121 publishers, and holds the world record for the most rejections for a popular (now classic) book with over five million copies sold. society. From the 1950 s whereby the USA had all-but recovered from the trauma of the Second World War, to the beginning and development of the Cold War. This Cold War climate, the Hot 'proxy' wars including the Korean War, and the beginning of the space race creating a politically conservative, some might say oppressive, climate.

As the 1950 s moved to the 1960 's ${ }^{10}$ the USA experienced hard fought battles by organised social movements to advance equity. Primarily relating to racism and sexism and as a reaction to the oppressive conservatism of the 1950s the development of the counterculture and revolutionary ideas surrounding social norms and centring on clothing, music, drugs, dress, sexuality, formalities, and schooling.

Moving into the 1970 s social progressive values that began in the $1960 \mathrm{~s}^{11}$ continued to grow. However, after $1974 \mathrm{a}$ new attitude towards atomised individualism and away from communitarianism began to develop in clear contrast with the 1960s.

These societal changes cannot be ignored, serving as the medium by which Pirsig's experiences occur, and which are discussed and presented in ZAMM. In a 2006 interview Pirsig tells us that

'It was a contest, I believe, between these ideas I had and what I see as the cultural immune system. When somebody goes outside the cultural norms, the culture has to protect itself.' [1]

\footnotetext{
${ }^{10}$ This decade is more loosely defined than the actual decade, beginning around 1963 and ending around 1974

${ }^{11}$ Increasing political awareness and political and economic liberty of
} women. 
Indeed, these changes lead us to the differences of two major philosophical systems of the world. The classical philosophy of the West being that of analysis critical thinking and intellectual pursuits. And the romantic philosophy of the East being that of calm reflection, meditation, love, devotion and the heart. Pirsig's own personality split also shadows these two 'opposing' philosophical views.

We can see this mirrored large in classical $\mathrm{HCl}$ and 'the new UX' whereby individual perception and preference, changeable by the moment, might conflict with harder timeto-task style $\mathrm{HCl}$.

Pirsig 'hoped Lila [his second book] would force the 'metaphysics of quality' from the New Age shelves to the philosophy ones, but that has not happened. Though a website dedicated to his ideas boasts 50,000 posts, and there have been outposts of academic interest, he is disappointed that his books have not had more mainstream attention. 'Most academic philosophers ignore it, or badmouth it quietly, and I wondered why that was. I suspect it may have something to do with our insistence that "quality" can not be defined,' he says.' [1]

While ZAMM has yet to be adopted into the philosophical domain, it is, never the less, an important work of literature (if nothing else). Regardless of whether it takes-off as a UX teaching textbook. As most instructors know, teaching a new technical subject to a non technical audience can be problematic. Teaching a new technical subject to a technical audience can likewise be a difficult. But these problems can be overcome by 'piggy-backing' this new information on familiar books, popular books, or those which are more accessible [7].
Image Rights Unless otherwise stated, all third party images qualify as fair use under United States law Section 107 of the Copyright Act. These images are used here for comment, teaching, scholarship, and research. Further, the effect of their use upon the potential market for or value of the copyrighted work is negligible as the image quality and size have been dramatically reduced.

\section{References}

[1] Tim Adams. 2006. The interview: Robert Pirsig. The Guardian http://www.theguardian.com/books/2006/nov/19/ fiction. Accessed: 2015-10-15. (Archived by WebCite® at http://www.webcitation.org/6cll7g0Bd) (Nov 2006).

[2] Jeffrey Bardzell and Shaowen Bardzell. 2013. What is "Critical" About Critical Design?. In Proceedings of the SIGCHI Conference on Human Factors in Computing Systems (CHI '13). ACM, New York, NY, USA, 32973306. DOI : http://dx.doi.org/10.1145/2470654.2466451

[3] Creative Market. 2015. 10 Must-Read UX Books. creativemarket.com https://creativemarket.com/blog/2015/ 01/13/10-must-read-ux-books. Accessed: 2015-11-05. (Archived by WebCite at http://www.webcitation.org/ 6coAjm9wi) (Oct 2015).

[4] Daniel Fallman. 2011. The New Good: Exploring the Potential of Philosophy of Technology to Contribute to Human-computer Interaction. In Proceedings of the SIGCHI Conference on Human Factors in Computing Systems (CHI '11). ACM, New York, NY, USA, 10511060. DOI: http://dx.doi.org/10.1145/1978942.1979099

[5] David Gough, Sandy Oliver, and James Thomas (Eds.). 2012. An Introduction to Systematic Reviews (1 ed.). SAGE Publications Ltd. http://amazon.com/o/ASIN/ 1849201811/

[6] Effie Lai-Chong Law, Virpi Roto, Marc Hassenzahl, Arnold P.O.S. Vermeeren, and Joke Kort. 2009. Understanding, Scoping and Defining User Experience: 
A Survey Approach. In Proceedings of the SIGCHI Conference on Human Factors in Computing Systems (CHI '09). ACM, New York, NY, USA, 719-728. DOI : http://dx.doi.org/10.1145/1518701.1518813

[7] John Leland. 2008. Motorhead. The New York Times http://www.nytimes.com/2008/09/28/books/review/Leland-t. html. Accessed: 2015-10-15. (Archived by WebCite ${ }$ at http://www.webcitation.org/6cllk5gAx) (Sept 2008).

[8] William McNeill. 1999. The Glance of the Eye: Heidegger, Aristotle, and the Ends of Theory (SUNY Series in Contemporary Continental Philosophy) (SUNY Series in Contemporary Continental Philosophy (Paperback)). State University of New York Press.

[9] Ryan Nance. 2015. 10 Non-UX Books

for Experience Designers. Medium.com -
User Experiences https://userexperiences.co/

10-non-ux-books-for-experience-designers-68acc18df046\# .z24ezvuat. Accessed: 2015-11-04. (Archived by WebCite at http://www.webcitation.org/6cmqGrWvX) (Oct 2015).

[10] Robert M. Pirsig. 1990. Zen and the Art of Motorcycle Maintenance: An Inquiry into Values. Vintage.

[11] Tim Wilson. 2014. A fresh look at Robert Pirsig's Zen and the Art of Motorcycle Maintenance. CBC News http://www.cbc.ca/news/arts/ a-fresh-look-at-robert-pirsig-s-zen-and-the-art-of-motorcycle-maintenance-1. 2856138. Accessed: 2015-10-15. (Archived by WebCite $\AA$ at http://www.webcitation.org/6cllzE241) (Dec 2014). 